\title{
Screening of Antimicrobial Resistance Genes and Epidemiological Features in Hospital and Community-Associated Carbapenem Resistant Pseudomonas aeruginosa Infections
}

ayse erturk ( $\square$ ayseace25@gmail.com )

RECEP TAYYIP ERDOGAN UNIVERSITY

Ayşegül Çopur ÇiçEK

Recep Tayyip Erdoğan University

Nebahat EJDER

Recep Tayyip Erdo?an University: Recep Tayyip Erdogan Universitesi

Uğur KOSTAKOĞLU

Recep Tayyip Erdoğan University: Recep Tayyip Erdogan Universitesi

İlknur Esen YILDIZ

Recep Tayyip Erdoğan University: Recep Tayyip Erdogan Universitesi

Songül ÖZYURT

Recep Tayyip Erdoğan University: Recep Tayyip Erdogan Universitesi

Emine SÖNMEZ

Recep Tayip Erdoğan University

Alper KARAGÖZ

Uşak Üniversitesi: Usak Universitesi

Research

Keywords: Pseudomonas aeruginosa , antibiotic resistance genes, epidemiology, PFGE

Posted Date: November 17th, 2020

DOl: https://doi.org/10.21203/rs.3.rs-103545/v1

License: (c) (i) This work is licensed under a Creative Commons Attribution 4.0 International License.

Read Full License 


\section{Screening of Antimicrobial Resistance Genes and Epidemiological Features in Hospital and Community-Associated Carbapenem Resistant Pseudomonas aeruginosa Infections}

Ayşe Ertürk ${ }^{1}$, Ayşegül Çopur Çiçek ${ }^{2}$, Nebahat Ejder $^{2}$, Uğur Kostakoğlü ${ }^{1}$, İlknur Esen Yıldız ${ }^{1}$, Songül Özyurt ${ }^{3}$, Emine Sönmez ${ }^{1 *}$, Alper Karagöz ${ }^{4}$

${ }^{1}$ Recep Tayyip Erdogan University, Faculty of Medicine, Department of Infectious Diseases and Clinical Microbiology, Rize, Turkey

${ }^{2}$ Recep Tayyip Erdogan University, Faculty of Medicine, Department of Medical Microbiology, Rize, Turkey

${ }^{3}$ Recep Tayyip Erdogan University, Faculty of Medicine, Department of Chest Diseases, Rize, Turkey

${ }^{4}$ Uşak University, Faculty of Sciences and Arts, Department of Molecular Biology and Genetics, Uşak, Turkey

\section{*Correspondence: ayseace25@gmail.com}

25 


\section{Abstract}

Background: Researching carbapenem-resistant isolates and the use of antibiotics and following infection control policies enable the identification of carbapenemase-producing bacteria and prevent their spread.

Methods: P. aeruginosa isolates were recovered from Medicine Faculty of Recep Tayyip Erdoğan University between April 2015 and October 2016 and identified by conventional methods and the automated Vitek 2 Compact (BioMerieux, France) system. Antimicrobial susceptibility experiments were performed in accordance with CLSI criteria and the automated Vitek 2 Compact system. The PCR method was investigated for the presence of $\beta$-lactamase resistance genes. PFGE typing was performed to show clonal relation among samples.

Results: Seventy P. aeruginosa strains were isolated from seventy patients. The median age of 70 cases was found 66 with minimum 17 and maximum 92 years old. $67.1 \%$ of the patients had contact with the health service in the last 90 days and $75.7 \%$ of the patients had received antimicrobial therapy in the previous 90 days. The most common comorbidity was cardiovascular diseases. Twenty-four $(34.3 \%)$ strains were carbapenem resistant, 2 strains were multidrug-resistant except colistin, and none of the samples had colistin resistance. The gene encoding $\beta$-lactamase or metallo- $\beta$-lactamase was found in a total of 36 strains. The bla $\mathrm{VEB}_{\mathrm{B}}$ gene was identified in only 1 strain alone, but in combination with other resistance genes in a total of 17 strains. While the bla alone, it was found in 13 samples in combination with other genes. Among the genes encoding metallo$\beta$-lactamase, the most bla $a_{\text {NDM }}$ positive was detected $(n=22)$, followed by 14 positive samples of bla $\mathrm{KPC}$. bla $_{\mathrm{IMP}}$ and bla $a_{\mathrm{VIM}}$ were detected in 5 and 1 samples, respectively. Also, the association of bla $a_{\mathrm{VEB}}-b_{l} a_{\mathrm{PER}}$

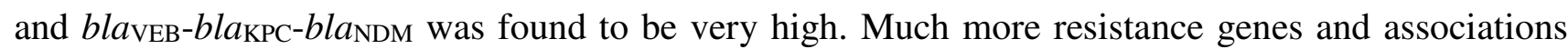
were detected in hospital-acquired samples than community-acquired samples, both proportionally and in terms of co-occurrence. Most of the community-associated strains were collected in the F2 clade, while most of the hospital-associated strains were collected in the G1 clade. However, no difference was found between the community and hospital-associated strains according to PFGE results. Simultaneously, other microorganisms were also isolated from patients from which these $6 P$. aeruginosa strains were isolated. Of these patients, 5 patients died, except the number 70 .

Conclusions: The median length of stay (days) was found to be significantly higher in the group with HAI than in the group with CAI. Compared to sample 28 and 37, which carried $5 \beta$-lactamase coding genes, the death of these 5 patients with fewer or no resistance genes showed that the coexistence of other factors - especially other microorganisms in addition to resistance genes, was important.

Keywords: Pseudomonas aeruginosa, antibiotic resistance genes, epidemiology, PFGE 


\section{Background}

Pseudomonas aeruginosa is an opportunistic gram-negative bacteria commonly found on many surfaces. Its rapid colonization on living and non-living areas leads to a wide range of causative pathogenities, including community and health-associated infections $[1,2]$. P. aeruginosa is very difficult to control in the hospital environment due to its versatile and ubiquitous bacterium feature [3]. P.aeruginosa infections are significantly increased in exposure to healthcare units in chronic diseases (eg cystic fibrosis), immunocompromised patients (eg burns, hematological malignancies) [1, 3].

Infections caused by $P$. aeruginosa are difficult to treat because of the intrinsic resistance of the bacterium to many antipseudomonal agents and its ability to easily acquire antibiotic resistance [4]. In hospital infections caused by $P$. aeruginosa strains with multiple drug resistance, mortality, hospitalization, and treatment costs increase, especially in intensive care units. Mortality decreases significantly if early and appropriate antipseudomonal treatment is initiated [5,6]. Carbapenems are powerful broad-spectrum- $\beta$-lactam antibiotics commonly used in the treatment of $P$. aeruginosa. However, increased carbapenem resistance among these organisms has been found worldwide, and carbapenem-resistant $P$. aeruginosa ranges from $10 \%$ to $50 \%$ in most countries. Few antibiotic options are available for treatment, and multidrug resistance is much more common in patients infected with carbapenem-resistant $P$. aeruginosa $[7,8]$.

In this study, it was aimed to determine the antimicrobial resistance profile of $P$. aeruginosa strains isolated from culture samples sent from various polyclinics and services in a university hospital and thought to be an infectious agent of community (CAI) and hospital-associated (HAI), to screen the resistance genes and to investigate the clonal relationship between isolates.

\section{Materials and Methods}

\section{Bacterial isolates and identification}

Seventy clinical $P$. aeruginosa isolates were recovered from different units (the intensive care burn unit, blood, urine, wound swab sample, sputum, tracheal aspirate, cerebrospinal fluid (CSF), bronchoalveolar lavage) in Medicine Faculty of Recep Tayyip Erdoğan University between April 2015 and October 2016. The clinical data of the patients were obtained retrospectively from file records and medical tables. One sample of each patient classified as a hospital (HAI) and community-associated (CAI) was evaluated. The isolates were identified by conventional methods and the automated Vitek 2 Compact (BioMerieux, France) system. This study was approved by the Scientific and Ethical Committee of Rize Recep Tayyıp Erdogan University Clinical Research Ethics Committee (Rize, 
Turkey) (40465587-32 /2018-32).

\section{Antibiotic susceptibility testing}

Antimicrobial susceptibility experiments were performed in accordance with CLSI (Clinical and Laboratory Standards Institute) criteria using both the Kirby-Bauer disc diffusion method and the automated Vitek 2 Compact (BioMerieux, France) system. In this context, amikacin (AK), gentamicin (GN), ciprofloxacin (CIP), ceftazidime (CAZ), piperacillin (PRL), piperacillin-tazobactam (TZP), aztreonam (ATM), meropenem (MEM), cefepime (FEP) and imipenem (IPM) sensitivity was evaluated. $P$. aeruginosa ATCC 27853 was used as a quality control strain.

\section{Detection of $\beta$-lactamase encoding resistance genes}

The PCR method was investigated for the presence of resistance genes. To obtain template DNA, a single colony bacterial strains were inoculated into $3 \mathrm{~mL}$ of Luria-Bertani (LB) broth medium (1\% tryptone, $0.5 \%$ yeast extract, $0.5 \% \mathrm{NaCl}, \mathrm{pH} 7.4$ ) at $37^{\circ} \mathrm{C}$ for 16 hours at $200 \mathrm{rpm}$. One and half $\mathrm{mL}$ of the grown culture was transferred to eppendorf tubes and centrifuged at $10000 \mathrm{rpm}$ for 5 minutes in microcentrifuge. The supernatant part was poured and $1 \mathrm{~mL}$ of sterile distilled water was added to the pellet and vortexed (twice). One $\mathrm{mL}$ of sterile distilled water was added to the pellet and the bacterial suspension was boiled at $95{ }^{\circ} \mathrm{C}$ for 10 minutes. After boiling, the bacteria suspension was centrifuged at $13000 \mathrm{rpm}$ for 5 minutes. Three $\mu \mathrm{l}$ of the supernatant part was used as template DNA in PCR. Standard PCR mixtures were $50 \mu \mathrm{l}$ final volume; 1,5 units Taq DNA polymerase I (Solis Biodyne), 5 $\mu 1$ DNA, $10 \mu 1$ XX DNA polymerase buffer (Solis Biodyne), $3 \mu 1$ of $25 \mathrm{mM} \mathrm{MgCl}_{2}, 2.5 \mu 1$ of $4 \mathrm{mM}$ each dNTP and $1 \mu \mathrm{l}$ each primer stock $(10 \mathrm{pmol} / \mu \mathrm{l})$ and final volume of sterile deionized water was prepared by completing. Amplification conditions; 3 min $94{ }^{\circ} \mathrm{C}$ initial denaturation, $94{ }^{\circ} \mathrm{C} 45 \mathrm{sec}$ denaturation, $55^{\circ} \mathrm{C} 1 \mathrm{~min}$ binding, $3 \mathrm{~min} 70^{\circ} \mathrm{C}$ elongation ( 34 cycles) and final synthesis $5 \mathrm{~min} 70^{\circ} \mathrm{C}$. Amplification products were run in 1.5-2\% agarose gel and visualized with UV. The oligonucleotides used in PCR and their Tm are given in the Table 1.

\section{Table 1}

\section{Molecular typing of the P. aeruginosa strains}

PFGE typing was performed on 70 strains to show clonal relation among samples. Isolation and deproteinization of the genomic DNA were done following the protocol of Durmaz et al with minor modifications [16]. Briefly, P. aeruginosa colonies on muller hilton agar were suspendedin $1 \mathrm{~mL}$ HST 
(100mm Tris-HCl, 100mm EDTA, pH 8.0 ) and the optical density was adjusted to 0.8 (590 nm). The cells were embedded into low (2\%) melting agarose. Molds were prepared with the help of agarose and kept in the refrigerator at $4{ }^{\circ} \mathrm{C}$ for 10 minutes. The prepared strain molds were added HLS-1 (50 $\mathrm{mm}$ Tris- $\mathrm{HCl}, 50 \mathrm{~mm}$ EDTA, $\mathrm{pH}$ 8.0, $2.5 \mathrm{mg} / \mathrm{ml}$ Lysozyme, $1.5 \mathrm{mg} / \mathrm{ml}$ Proteinase $\mathrm{K}$ ) and incubated at $37^{\circ} \mathrm{C}$ for 1 hour in a water bath. At the end of the period, HLS-1 was removed. HLS-2 (0.5 M EDTA, $1 \%$ sarcosyl, $400 \mu \mathrm{g} / \mathrm{ml}$ Proteinase $\mathrm{K}$ ) was placed on molds and incubated in a water bath at $55^{\circ} \mathrm{C}$ for 2 hours. After the lysis step, the molds were washed 3 times each with $\mathrm{dH}_{2} \mathrm{O}$ and 1 XTE (Tris-EDTA). After digestion of the cells and washing of the plugs, genomic DNA in the agarose plugs was restricted by $10 \mathrm{U}$ of SpeI (Thermo) for 3 hours at $37{ }^{\circ} \mathrm{C}$ in a incubator. DNA frag-ments were separated on $1 \%$ pulse-field certified agarose (BIO-RAD) gels run in 0.5X Tris-borate-EDTA buffer (44.5 mM/LTris, $44.5 \mathrm{mM} / \mathrm{L}$ boric acid, $1 \mathrm{mM} / \mathrm{L}$ EDTA [pH8.0]) by using a CHEF-DR II system (Bio-Rad Laboratories). The electrophoresis conditions were $14^{\circ} \mathrm{C}$ at $6 \mathrm{~V} / \mathrm{cm}^{2}$ for 18 hours. The initial and final switch timeswere 5 seconds and 20 seconds, respectively. The gel was stained with ethidium bromide $(5 \mathrm{mg} / \mathrm{mL})$ for 30 mins and pho-tographed under UV light. The DNA band profiles were analyzed with Gel Compar software (version 3.0; Applied Maths, Sint-Martens-Latem, Belgium) dendogram and Dice Accordingto the interpretative criteria of Tenover et al, isolates were classified as indistinguishable (cluster), closely related, possibly related, or different [17].

\section{Statistical analysis}

SPSS 21.0 (NY IBM Corp., 2012) program was used. Categorical variables were expressed in terms of frequency (n) and percentage (\%). The fitness of continuous variables to normal distribution was tested with Kolmogorov-Simirnov and expressed in terms of arithmetic mean, standard deviation, median, minimum and maximum values. While Mann-Whitney U test was used in paired comparison of continuous variables, categorical variables were analyzed with Pearson $\chi 2$ and Fisher's exact tests. $\mathrm{P}<.05$ significance level was accepted.

\section{Results and Discussion}

\section{Epidemiological results}

One sample from each patient was accepted into the study. The median age of 70 cases was 66 with minimum 17 and maximum 92 years old. The median age of HAI and CAI were $38.6 \%(n=27)$ and 
$61.4 \%(\mathrm{n}=43)$ respectively (Table 2$)$. The two groups were similar in terms of age distribution $(\mathrm{z}=-$ 1.829, $\mathrm{p}=0.067)$ and the two groups were found to be similar in terms of gender distribution $\left(\chi^{2}(1)=\right.$ $.509, \mathrm{p}=0.476$ ). The median length of stay (days) was found to be significantly higher in the group with HAI than in the group with CAI (22 vs. 18 days, $\mathrm{z}=-2.192, \mathrm{p}=0.003)$. Thirty three strains $(47.1 \%)$ were isolated from respiratory secretions and most of them were respiratory infections ( $n=16$ communityacquired pneumonia (CAP) and $n=13$ ventilator-associated pneumonia (VAP)). $67.1 \%$ of the patients had contact with the health service in the last 90 days and $75.7 \%$ of the patients had received antimicrobial therapy in the previous 90 days. The most common comorbidity was cardiovascular diseases $(38.6 \%)$.

\section{Table 2}

Respiratory pathologies constituted $27.1 \%(n=19)$ of the patients in the distribution of the first (preliminary) diagnosis at the time of admission to the hospital, other diagnoses were urinary system infections (18.6\%, $\mathrm{n}=13)$, neurological pathologies (12.9\%, n=9 ) Gastro Intestinal System (GIS) pathologies $(11.4 \%, \mathrm{n}=8)$, Cardiovascular System (CVS) pathologies $(8.6 \% \mathrm{n}=6)$, trauma $(8.6 \% \mathrm{n}=6)$ skin-soft tissue pathologies $(7.1 \% \mathrm{n}=5)$ and oncological pathologies $(5.7 \% \mathrm{n}=4)$ (Table 3). When the two groups were evaluated in terms of the distribution of hospitalization indications, it was found that the most complaint was respiratory failure $(n=14)$ and the presence of mental change was significant in the HAI group $(\chi 2(1)=6.756$, Fisher's exact test, $p=0.019)$. The history of hospital contact and use of antibiotics in the last 3 months was high in all patients $(67.1 \%, 75.7 \%$, respectively). While $33.3 \%$ $(n=9)$ of patients with HAI had an operative history in the last one month. This rate was $14 \%(n=6)$ in cases with TAI $(\chi 2(1)=3.700, p=0.054)$. The detailed descriptions of demographic and pathological characteristic of HAI and CAI could be found in Table 3.

\section{Table 3}

Considering the invasive procedures and applications during the $P$. aeruginosa isolation period, the presence of decubitus with hemodialysis, endotracheal tube application, nasogastric tube application, perpheric artery catheter application, urinary catheter and mechanical ventilator applications was found to be significantly higher in the HAI group compared to the CAI group ( $\mathrm{p}<0.01)$. Bronchoscopy was performed on HAI patients but it was not performed on CAI patients. It was found to be significantly higher as a risk factor in patients with HAI $(\mathrm{p}=0.038)$. The rate of performing cystostomy was similar 
in both groups. The detailed descriptions of diagnosis, clinical features and risk factors of HAI and CAI groups could be found in Table 4.

\section{Table 4}

\section{Antibiotic susceptibility}

Thirteen antimibiotics were used to determine the resistance phenotype of $70 P$. aeruginosa in this study (Table 5). While the highest resistance was observed against piperacillin $(\mathrm{n}=36)$, colsitin resistance was not observed in any strain. Twenty-four (34.3\%) strains were carbapenem resistant.

\section{Table 5}

\section{Detection of MBLs}

Carbapenems are used as the last resort for the treatment of infections caused by these pathogens. However, $P$. aeruginosa is capable of producing enzymes, such as MBL, that inactivate carbapenems. When the resistance genes of the isolates were scanned, the gene encoding $\beta$-lactamase or metallo- $\beta$ lactamase was found in a total of 36 strains. The blaveB gene was identified in only 1 strain alone, but in combination with other resistance genes in a total of 17 strains (Table 6). While the bla $a_{\text {PER gene was }}$ detected in 5 samples alone, it was found in 13 samples in combination with other genes. Neither blavEB nor bla $a_{\mathrm{PER}}$ was detected in 9 samples. Among the genes encoding metallo- $\beta$-lactamase, the most $b l a_{\mathrm{NDM}}$ positive was detected $(\mathrm{n}=22)$, followed by 14 positive samples of bla $\mathrm{KPC}$. bla $\mathrm{IMP}$ and blaviM were

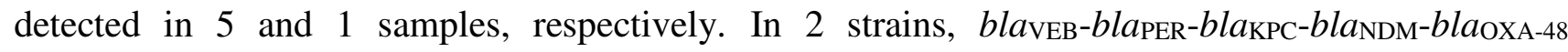
combination was found. Also, the association of bla $a_{\mathrm{VEB}}-b_{l} a_{\mathrm{PER}}$ and bla $_{\mathrm{VEB}}-b_{l} a_{\mathrm{KPC}}-b_{l} a_{\mathrm{NDM}}$ was found to be very high. Much more resistance genes and associations were detected in hospital-acquired samples than community-acquired samples, both proportionally and in terms of co-occurrence.

\section{Table 6.}

\section{Clonal relationship}

Clonal association was investigated with a total of 6 gel images and 7 major PFGE profiles were identified (Fig. 1). When looked clonally, 43 strains were found to be related under major $F$ group. The F1 subgroup is divided into 3 patterns (F1a, F1b, F1c). When the relationship with the F1 subgroup is examined, it is also closely related to this group according to the $85 \%$ Tennover criteria. Group A, 2 (A1-A2); Group F, 2 (F1-F2); Group G is divided into 2 (G1-G2) subgroups. In particular, six strains 
$(65,66,67,68,69,70$ and 6 strains) were included in the group of 20 strains classified as F2 in the major F group. The 6 strains mentioned above are 100\% associated with 14 strains in the F2 major group $(51,52,53,54,55,56,57,58,59,60,61,62,63,64)$. Most community-associated strains were collected in the F2 clade, while most hospital-associated strains were collected in the G1 clade. However, no difference was found between the community and hospital-associated strains according to PFGE results.

\section{Fig. 1}

Simultaneously, other microorganisms were also isolated from patients from which these $6 P$. aeruginosa strains were isolated. Of these patients, 5 patients died, except the number 70. Acinetobacter spp., / K. pneumoniae, Acinetobacter spp., Candida spp., Acinetobacter spp., / K. pneumoniae, Acinetobacter spp. and Klebsiella spp., microorganisms were also detected in patients with numbers 65, 66, 67, 68, 69 and 70 respectively. While samples numbered 65, 66, and 67 of these patients were community-associated, samples 68, 69 and 70 were hospital-associated. Among these six samples, bla $a_{\mathrm{PER}} / b l a_{\mathrm{VEB}}, b_{1} a_{\mathrm{KPC}}, b_{l a}{ }^{\mathrm{OXA}-51}$ and bla $a_{\mathrm{NDM}}$ resistance genes were detected in $65,66,67$ and 68 , respectively, while no resistance gene was detected in sample 69 and 70. Other information about the patients from whom 6 strains were isolated are as in Table 7. Compared to sample 28 and 37, which carried $5 \beta$-lactamase coding genes, the death of these 5 patients with fewer or no resistance genes showed that the coexistence of other factors - especially other microorganisms in addition to resistance genes, was important.

\section{Table 7}

Since $P$. aeruginosa and Acinetobacter species producing extended-spectrum $\beta$-lactamase (ESBL) are resistant to most $\beta$-lactam antibiotics, monitoring and control of its spread is important when such $\beta$-lactamase occurs. Since a limited number of antibiotics such as antipseudomonal penicillins and cephalosporins, aminoglycosides, fluoroquinolones and carbapenems are effective on $P$. aeruginosa, it is important to monitor and control the spread of genes that cause resistance to these drugs [18]. It is essential to define the main risk groups as well as the genetic data of the strains [17]. According to the European Center for Disease Prevention and Control (ECDC) in 2016, P. aeruginosa resistance in most European countries exceeded $10 \%$ of all antimicrobials studied. Moreover, the prevalence of MDR- $P$. aeruginosa is increasing globally, mainly due to nosocomial outbreaks and 
transferable resistance mechanisms, a phenomenon associated with the spread of high-risk clones, especially horizontally acquired (by multiple loci sequence types ST235, ST111, ST175). Despite its low antibiotic consumption comparable to other Northern European countries [19] resistance rates of PA in Estonia, especially to carbapenems, are much higher than in other low-end use countries, and trends are becoming alarming. In 2012, $12.5 \%$ of the strains reported to the ECDC were carbapenem resistant (CR), but this had risen to over $20 \%$ by 2016 [20, 21]. Although the main trigger associated with CR in $P$. aeruginosa is the production of plasmid-mediated $\beta$-lactamases / carbapenemases, mutational resistance mechanisms in chromosomal genes - for example, altered expression of outer membrane porins or flux system and increased chromosomal cephalosporinase (AmpC) activity may all be affected.

\section{Conclusion}

In Turkey, the period of 2011-2016, the overall carbapenem resistance has varied between 42.9\% 30.26-\%. In 2016, T.C. Ministry of Health Public Health Agency of Turkey National Nosocomial Infections Surveillance Network Summary Report was published. Carbapenem resistance in P. aeruginosa across Turkey was determined to be $35.65 \%$. In the University hospitals where our study was conducted, it was $36.55 \%$ (50-75 percentile), with a median of $35.71 \%$ and $45.28 \%$, respectively. In our study, carbapenem resistance was found $34.3 \%$ with compatible of the country's Median value $(50 \%)$ [22]. The median length of stay (days) was significantly higher in the group with HAI than in the group with CAI. Compared to sample 28 and 37, which carried $5 \beta$-lactamase coding genes, the death of these 5 patients with fewer or no resistance genes showed that the coexistence of other factors - especially other microorganisms in addition to resistance genes, was important.

\section{Abbreviations}

IMICU: Internal Medicine Intensive Care Unit; SICU: Surgical Intensive Care Unit; CVSICU: Cardio Vascular Surgery Intensive Care Unit; CICU: Coronary Intensive Care Unit; ARICU: Anesthesia and Reanimation Intensive Care Unit; OS; GIS: Gastro Intestinal System; CVS: Cardiovascular System; other services. CSF: cerebrospinal fluid, ARICU: Anesthesia and Reanimation Intensive Care Unit, IMICU: Internal Medicine Intensive Care Unit, PCU: Palliative Care Unit, IDS: Infectious Diseases Service, IVTA: In-Vehicle Traffic Accident, TSH: Traumatic Subarachnoid Hemorrhage, CRI: Chronic Renal Insufficiency, PTC: Percutaneous Transhepatic Cholangiography, TAC: Trekeal Aspiration Culture, NBS: Neurogenic Bladder with Sringomy; VIM: Verona integron-encoded MBL; NDM: New Delhi metallo- $\beta$-lactamase; MBLs: metallo- $\beta$-lactamases; Bla: $\beta$-lactamase; MHT: modified Hodge test; PCR: polymerase chain reaction; SIM: Seoul imipenemase; GIM: German 
imipenemase; SMB: Serratia metallo- $\beta$-lactamase; ESBL: extended spectrum $\beta$ lactamase; 5CS \& 3CS: 5' \& 3'-conserved segments; ISCR: insertion sequence common region; MIC: minimum inhibitory concentration; PFGE: pulse field gel electrophoresis; UTI: urinary tract infection; CLSI: Clinical and Laboratory Standards Institute

299

\section{Authors' contributions}

A.E, AÇÇ and A.K: Designed and drafted the manuscript. AE, AÇÇ, UK, IEEY, NJ: Performed the experiments. SÖ, ES, AK: analyzed the data. AE: AÇÇ, NE: AE, AÇÇ, NE: Collected samples. AE, AÇÇ, AK: Provided analysis methods.

\section{Author details}

${ }^{1}$ Recep Tayyip Erdogan University, Faculty of Medicine, Department of Infectious Diseases and Clinical Microbiology, Rize, Turkey. ${ }^{2}$ Recep Tayyip Erdogan University, Faculty of Medicine, Department of Medical Microbiology, Rize, Turkey. ${ }^{3}$ Recep Tayyip Erdogan University, Faculty of Medicine, Department of Chest Diseases, Rize, Turkey. ${ }^{4}$ Uşak University, Faculty of Sciences and Arts, Department of Molecular Biology and Genetics, Uşak, Turkey

\section{Acknowledgements}

This work was supported by Recep Tayyip Erdogan University Research Fund Grants (BAP).

\section{Competing interests}

The authors declare that they have no competing interests.

\section{Availability of data and materials}

Our data are available on request by contacting the corresponding author.

\section{Funding}

This study was supported by the Recep Tayyip Erdogan University-Scientific Research Projects Coordination Unit [Project number: TSA-2017-801].

\section{Ethics approval and consent to participate}

This study was approved by Scientific and Ethical Committee of Rize Recep Tayyıp Erdogan University Clinical Research Ethics Committee (Rize, Turkey) (40465587-32 /2018-32). 


\section{References}

1. Pachori P, Gothalwal R, Gandhi P. Emergence of antibiotic resistance Pseudomonas aeruginosa in intensive care unit; a critical review. Genes Dis. 2019;17:109-19.

2. Telling K, Laht M, Brauer A, Remm M, Kisand V, Maimets M, et al. Multidrug resistant Pseudomonas aeruginosa in Estonian hospitals. BMC Infect Dis. 2018;11:513.

3. Chairat S, Ben Yahia H, Rojo-Bezares B, Sáenz Y, Torres C, Ben Slama K. High prevalence of imipenem-resistant and metallo- $\beta$-lactamase-producing Pseudomonas aeruginosa in the Burns Hospital in Tunisia: detection of a novel class 1integron. J Chemother. 2019;31:120-6.

4. Hu Y, Cao Jm, Yang Q, Chen S, Lv H, Zhou H, et al. Risk Factors for carbapenem-resistant Pseudomonas aeruginosa, Zhejiang Province, China. Emerg Infect Dis. 2019;25:1861-7.

5. Bonnet V, Dupont H, Glorion S, Aupée M, Kipnis E, Gérard JL, et al. Influence of bacterial resistance on mortality in intensive care units: a registry study from 2000 to 2013 (IICU Study). J Hosp Infect. 2019;102:317-24.

6. Tabak YP, Merchant S, Ye G, Vankeepuram L, Gupta V, Kurtz SG, et al. Incremental clinical and economic burden of suspected respiratory infections due to multi-drug-resistant Pseudomonas aeruginosa in the United States. J Hosp Infect. 2019;19:30259-2.

7. Feng W, Sun F, Wang Q, Xiong W, Qiu X, Dai X, et al. Epidemiology and resistance characteristics of Pseudomonas aeruginosa isolates from therespiratory department of a hospital in China. J Glob Antimicrob Resist. 2017;8:142-7.

8. Karampatakis T, Tsergouli K, Politi L, Diamantopoulou G, Iosifidis E, Antachopoulos C, et al. Molecular epidemiology of endemic carbapenem-resistant gram-negative bacteria in an intensive care unit. Microb Drug Resist. 2019;25:712-6.

9. Moubareck C, Bre'mont S, Conroy MC, Courvalin P, Lambert T. GES-11, a novel integronassociated GES variant in Acinetobacter baumannii. Antimicrob Agents Chemother. 2009;53:357981.

10. Celenza G, Pellegrini C, Caccamo M, Segatore B, Amicosante G, Perilli M. Spread of blaCTX-Mtype and bla PER-2 $\beta$-lactamase genes in clinical isolates from Bolivian hospitals. J Antimicrob Chemother. 2006;57:975-8.

11. Jeon BC, Jeong SH, Bae IK, Kwon SB, Lee K, Young D. Investigation of a nosocomial outbreak of imipenem-resistant Acinetobacter baumannii producing the OXA-23 $\beta$-lactamase in Korea. J Clin Microbiol. 2005;43:2241-5.

12. Cicek AC, Saral A, Iraz M, Ceylan A, Duzgun AO, Peleg AY, et al. OXA and GES-type $\beta$ lactamases predominate in extensively drug-resistant Acinetobacter baumannii isolates from a Turkish University Hospital. Clin Microbiol Infect. 2014;20:410-5.

13. Poirel N, He'ritier C, Tolun V, Nordmann P. Emergence of oxacillinase-mediated resistance to imipenem in Klebsiella pneumoniae. Antimicrob Agents Chemother. 2004;48:15-22.

14. Poirel L, Walsh TR, Cuvillier V, Nordmann P. Multiplex PCR for detection of acquired carbapenemase genes. Diagn Microbiol Infect Dis. 2011;70:119-23. 
15. Woodford N, Ellington MJ, Coelho JM, Turton JF, Ward ME, Brown S, et al., Multiplex PCR for genes encoding prevalent OXA carbapenemases in Acinetobacter spp. Int $\mathrm{J}$ Antimicrob Agents. 2006;2:351-3.

16. Durmaz R, Otlu B, Koksal F, Hosoglu S, Ozturk R, Ersoy Y, et al. The optimization of a rapid pulsed-field gel electrophoresis protocol for the typing of Acinetobacter baumannii, Escherichia coli and Klebsiella spp. Jpn J Infect Dis. 2009;62:372-7.

17. Tenover FC, Arbeit RD, Goering RV, Mickelsen PA, Murray BE, Persing DH, et al. Interpreting chromosomal DNA restriction patterns pro-duced by pulsed-field gel electrophoresis: criteria for bacterial straintyping. J Clin Microbiol. 1995;33:2233-9.

18. Atilla A, Eroğlu C, Esen S, Sünbül M, Leblebicioğlu H. Investigation of the frequency of PER-1 type $\beta$-lactamase and antimicrobial resistance rates in nosocomial isolates of Pseudomonas aeruginosa. Mikrobiyol Bul. 2012;46:1-8.

19. URL-1, Antimicrobial consumption database (ESAC-Net). http://ecdc.europa.eu/en/ antimicrobial-consumption/surveillance-and-disease-data/database.

20. URL-2, Antimicrobial resistance surveillance in Europe 2016. http://ecdc.europa.eu/ en/publications-data/antimicrobial-resistance-surveillance-europe-2016.

21. URL-3, Antimicrobial resistance surveillance in Europe 2012. http://ecdc.europa.eu/ en/publications-data/antimicrobial-resistance-surveillance-europe-2012.

22. URL-4, https://infline.saglik.gov.tr/login.aspx

(1)


Table 1 Primers used in the amplification of selected genes

\begin{tabular}{|c|c|c|c|c|}
\hline Primer & 5'-3' Sequence & $\begin{array}{l}\text { Amplicon } \\
\text { Size (bp) }\end{array}$ & $\begin{array}{l}\text { Tm } \\
\left({ }^{\circ} \mathrm{C}\right)\end{array}$ & Reference \\
\hline \multirow{2}{*}{ VEB } & F- ATTTCCCGATGCAAAGCGT & \multirow{2}{*}{542} & \multirow{2}{*}{55} & \multirow{2}{*}[9]{} \\
\hline & R- TTATTCCGGAAGTCCCTGT & & & \\
\hline \multirow{2}{*}{ PER } & F- ATGAATGTCATCACAAAAT & \multirow{2}{*}{927} & \multirow{2}{*}{50} & \multirow{2}{*}[10]{} \\
\hline & R- TCAATCCGGACTCACT & & & \\
\hline \multirow{2}{*}{ IMP } & F:CATGGTTTGGTGGTTCTTGT & \multirow{2}{*}{488} & \multirow[b]{2}{*}{56} & \multirow{2}{*}[11]{} \\
\hline & R:ATAATTTGGCGGACTTTGGC & & & \\
\hline \multirow{2}{*}{ VIM } & F:ATTGGTCTATTTGACCGCGTC & \multirow{2}{*}{780} & \multirow{2}{*}{58} & \multirow{2}{*}[11]{} \\
\hline & R:TGCTACTCAACGACTGAGCG & & & \\
\hline \multirow{2}{*}{ NDM } & F:TGGAATTGCCCAATATTATGC & \multirow{2}{*}{813} & \multirow{2}{*}{54} & \multirow{2}{*}[12]{} \\
\hline & R:TCAGCGCAGCTTGTCGGCCATGC & & & \\
\hline \multirow{2}{*}{ KPC } & F: CGTTCTTGTCTCTCATGGCC & \multirow{2}{*}{796} & \multirow{2}{*}{52} & \multirow{2}{*}[13]{} \\
\hline & R: CCTCGCTGTGCTTGTCATCC & & & \\
\hline \multirow{2}{*}{ OXA-48 } & F:CAGTCAAGTTCAACCCAACCG & \multirow{2}{*}{438} & \multirow{2}{*}{55} & \multirow{2}{*}[14]{} \\
\hline & R:GCGTGGTTAAGGATGAACAC & & & \\
\hline \multirow{2}{*}{ OXA- 51} & F: TAATGCTTTGATCGGCCTTG & \multirow{2}{*}{353} & \multirow{2}{*}{52} & \multirow{2}{*}[15]{} \\
\hline & R:TGGATTGCACTTCATCTTGG & & & \\
\hline OXA-23 & $\begin{array}{l}\text { F:GATCGGATTGGAGAACCAGA } \\
\text { R:ATTTCTGACCGCATTTCCAT }\end{array}$ & 501 & 52 & {$[15]$} \\
\hline
\end{tabular}

407

408

409

410

411

412

413

414

Table 2 Distribution of cases according to service and intensive care units

\begin{tabular}{lccc}
\hline & Total $(\mathbf{n}=\mathbf{7 0})$ & HAI $(\mathbf{n}=\mathbf{2 7})$ & CAI $(\mathbf{n}=\mathbf{4 3})$ \\
\cline { 1 - 1 } Services, $\mathbf{n}(\%)$ & & & \\
\cline { 1 - 3 } IMICU & $14(20.0)$ & $11(40.7)$ & $3(7.0)$ \\
SICU & $12(17.2)$ & $8(29.6)$ & $4(9.3)$ \\
ARICU & $4(5.7)$ & $3(11.1)$ & $1(2.3)$ \\
CVSICU & $3(4.3)$ & $1(3.7)$ & $2(4.7)$ \\
CICU & $2(2.8)$ & $1(3.7)$ & $1(2.3)$ \\
Other services & $35(50.0)$ & $3(11.1)$ & $32(74.4)$ \\
\hline
\end{tabular}


Table 3 Comparison of demographic and pathological characteristics of HAI $(n=27)$ and CAI $(n=43)$ groups

\begin{tabular}{|c|c|c|c|c|c|}
\hline & Total & HAI & CAI & Statistics & \\
\hline & $n=70$ & $\mathrm{n}=\mathbf{2 7}$ & $n=43$ & $\mathrm{z}, \chi^{2}$ & p value \\
\hline Age (year) & $66(17-92)$ & $73(18-92)$ & $64(17-89)$ & -1.829 & .067 \\
\hline Over 65 years old & & $16(81 \pm 6.9)$ & $20(75 \pm 6.6)$ & (\%95 confidal) & .0013 \\
\hline Duration of stay (days) ${ }^{\mathrm{a}}$ & $19.5(1-72)$ & $22(14-72)$ & $18(1-39)$ & -2.921 & .003 \\
\hline \multicolumn{6}{|l|}{ Gender } \\
\hline Women & $27(38.6)$ & $9(33.3)$ & $18(41.9)$ & .509 & .476 \\
\hline Male & $43(61.4)$ & $18(66.7)$ & $25(58.1)$ & & \\
\hline Surgery history (last 1 month) & $15(21.4)$ & $9(33.3)$ & $6(14.0)$ & 3.700 & .054 \\
\hline Hospital history (last 3 months) & $47(67.1)$ & $16(59.3)$ & $31(72.1)$ & 1.238 & .266 \\
\hline $\begin{array}{l}\text { Antibiotic utilization (last } 3 \\
\text { months) }\end{array}$ & $53(75.7)$ & $22(81.5)$ & $31(72.1)$ & .795 & .373 \\
\hline First (Pre) diagnosis, n (\%) & & & & - & - \\
\hline Respiratory pathologies & $19(27.1)$ & $10(37.0)$ & $9(20.9)$ & & \\
\hline Urinary pathologies & $13(18.6)$ & 0 & $13(30.2)$ & & \\
\hline Urinary pathologies & $9(12.9)$ & $5(18.5)$ & $4(9.3)$ & & \\
\hline GIS problem & $8(11.4)$ & $5(18.5)$ & $3(7.0)$ & & \\
\hline CVS pathology & $6(8.6)$ & $2(7.4)$ & $4(9.3)$ & & \\
\hline Trauma & $6(8.6)$ & $3(11.1)$ & $3(7.0)$ & & \\
\hline Soft-tissue pathologies & $5(7.1)$ & 0 & $5(11.6)$ & & \\
\hline Oncological pathologies & $4(5.7)$ & $2(7.4)$ & $2(4.7)$ & & \\
\hline \multicolumn{6}{|l|}{$\begin{array}{l}\text { Hospitalization indication, } \mathrm{n} \\
(\%)\end{array}$} \\
\hline Respiratory Failure & $14(20.0)$ & $6(22.2)$ & $8(18.6)$ & .136 & .713 \\
\hline Mental changes & $4(5.7)$ & $4(14.8)$ & 0 & $6.756^{*}$ & .019 \\
\hline Hemodynamic instability & $4(5.7)$ & $1(3.7)$ & $3(7.0)$ & $.330 *$ & .498 \\
\hline Post CPR & $7(10.0)$ & $4(14.8)$ & $3(7.0)$ & $1.132 *$ & .253 \\
\hline
\end{tabular}

423

a: Median (minimum-maximum), *: Fisher's exact test.

424

425

426

427

428

429

430

431

432

433

434

435

436

437

438

439

440 
Table 4 Diagnosis, clinical features and risk factors of HAI $(n=27)$ and CAI $(n=43)$ groups

\begin{tabular}{|c|c|c|c|c|c|}
\hline & \multirow{2}{*}{$\begin{array}{l}\text { Total } \\
\mathbf{n}=70\end{array}$} & \multirow{2}{*}{$\begin{array}{l}\text { HAI } \\
\mathbf{n}=\mathbf{2 7}\end{array}$} & \multirow{2}{*}{$\begin{array}{l}\text { CAI } \\
n=43\end{array}$} & \multicolumn{2}{|l|}{ Statistics } \\
\hline & & & & $z, \chi 2$ & p value \\
\hline \multicolumn{6}{|l|}{$\begin{array}{l}\text { Final diagnosis on the PA isolation date } \\
(\%)\end{array}$} \\
\hline VAP (ventilator-associated pneumonia) & $13(18.6)$ & $13(48.2)$ & 0 & - & - \\
\hline KSI (blood stream infection) & $6(8.6)$ & $6(22.2)$ & 0 & & \\
\hline HP (hospital pneumonia) & $6(8.6)$ & $6(22.2)$ & 0 & & \\
\hline HUTI (hospital urinary tract infection) & $1(1.4)$ & $1(3.7)$ & 0 & & \\
\hline UTI (urinary tract infection) & $16(22.9)$ & 0 & $16(37.2)$ & & \\
\hline CAP (community-associated pneumatic) & $16(22.9)$ & 0 & $16(37.2)$ & & \\
\hline STI (soft tissue infection) & $6(8.5)$ & 0 & $6(14.0)$ & & \\
\hline IAI (intra-abdominal infection) & $3(4.2)$ & 0 & $3(6.9)$ & & \\
\hline CBSI (community-bloodstream infection) & $2(2.9)$ & 0 & $2(4.7)$ & & \\
\hline Meningitis & $1(1.4)$ & $1(3.7)$ & 0 & & \\
\hline \multicolumn{6}{|l|}{ Comorbid patients, n (\%) } \\
\hline CVS diseases & $27(38.6)$ & $12(44.4)$ & $15(34.9)$ & .640 & .424 \\
\hline $\mathrm{KOAH}$ & $12(17.1)$ & $5(18.5)$ & $7(16.3)$ & $.059 *$ & .526 \\
\hline Neurological diseases & $9(12.9)$ & $5(18.5)$ & $4(9.3)$ & $1.257 *$ & .292 \\
\hline Diabetes mellitus & $9(12.9)$ & $3(11.1)$ & $6(14.0)$ & $.120 *$ & .517 \\
\hline Malignant diseases & $7(10.0)$ & $3(11.1)$ & $4(9.3)$ & $.060 *$ & .554 \\
\hline Renal diseases & $6(8.6)$ & $1(3.7)$ & $5(11.6)$ & $1.329 *$ & .394 \\
\hline Skin-soft tissue pathologies & $5(7.1)$ & $2(7.4)$ & $3(7.0)$ & $.005^{*}$ & .645 \\
\hline \multicolumn{6}{|c|}{$\begin{array}{l}\text { Invasive procedures and applications } \\
\text { during the PA isolation period, } n(\%)\end{array}$} \\
\hline Hemodialysis & $24(34.3)$ & $19(70.4)$ & $5(11.6)$ & 25.402 & .000 \\
\hline Endotracheal application & $27(38.6)$ & $23(85.2)$ & $4(9.3)$ & 40.307 & .000 \\
\hline Enteral nutrition & $49(70.0)$ & $16(59.3)$ & $33(76.7)$ & 2.415 & .120 \\
\hline Peripheral venous catheter & $48(68.6)$ & $18(66.7)$ & $30(69.8)$ & .074 & .786 \\
\hline Nasogastric & $26(37.1)$ & $16(59.3)$ & $10(23.3)$ & 9.209 & .002 \\
\hline Peripheral artery catheter & $24(34.3)$ & $19(70.4)$ & $5(11.6)$ & 25.402 & .000 \\
\hline Decubitus & $22(31.4)$ & $17(63.0)$ & $5(11.6)$ & 20.281 & .000 \\
\hline Central venous catheter & $21(30.0)$ & $11(40.7)$ & $10(23.3)$ & 2.415 & .120 \\
\hline Urinary catheter & $26(37.1)$ & $16(59.3)$ & $10(23.3)$ & 9.209 & .002 \\
\hline Mechanical ventilator & $21(30.0)$ & $17(63.0)$ & $4(9.3)$ & 22.742 & .000 \\
\hline Total parenteral nutrition & $14(20.0)$ & $3(11.1)$ & $11(25.6)$ & 2.171 & .141 \\
\hline Transfusion & $14(20.0)$ & $6(22.2)$ & $8(18.6)$ & .136 & .713 \\
\hline Cystostomy & 13 (18.6) & $6(22.2)$ & $7(16.3)$ & .387 & .534 \\
\hline Bronchoscopy & $7(10.0)$ & $7(16.3)$ & 0 & $4.884 *$ & .038 \\
\hline Steroid & $7(10.0)$ & $3(11.1)$ & $4(9.3)$ & $.060 *$ & .554 \\
\hline Tracheotomy & $3(4.3)$ & $1(3.7)$ & $2(4.7)$ & $.036^{*}$ & .671 \\
\hline Chest tube & $3(4.3)$ & 0 & $3(7.0)$ & $1.968 *$ & .279 \\
\hline
\end{tabular}


Table 5 Resistance rates of $P$. aeruginosa isolates

453

\begin{tabular}{llll}
\hline Antibiotics & Resistant & Sensitive & Medium sensitive \\
\hline Ceftazidim & $30(42.9)$ & $34(48.6)$ & $6(8.6)$ \\
Cefepim & $34(48.6)$ & $29(41,4)$ & $7(10.0)$ \\
Cefoperazone & $12(17.1)$ & $58(82.9)$ & 0 \\
Cefoperazone-sulbactam & $10(14.3)$ & $60(85.7)$ & 0 \\
Piperacillin & $36(51.4)$ & $30(42.9)$ & $4(5.7)$ \\
Piperacillin-tazobactam & $34(48.6)$ & $29(41.4)$ & $7(10.0)$ \\
Amikacin & $10(14.4)$ & $54(77.0)$ & $6(8.6)$ \\
Gentamycin & $12(17.1)$ & $54(77.0)$ & $4(5.7)$ \\
Ciprofloxacin & $18(25.7)$ & $47(67.2)$ & $5(7.1)$ \\
Levofloxacin & $28(40.0)$ & $38(54.3)$ & $4(5.7)$ \\
Colistin & 0 & $70(100)$ & 0 \\
Imipenem & $13(18.6)$ & $56(80.0)$ & $1(1.4)$ \\
Meropenem & $18(25.7)$ & $49(70.0)$ & $3(4.3)$ \\
\hline Carbapenem resistance & $24(34.3)$ & $46(65.7)$ & 0 \\
\hline
\end{tabular}

454

455

456

457

458

459

Table $6 \beta$-lactamase genes identified in P. aeruginosa strains

\begin{tabular}{llc}
\hline Genes & Strain numbers & $\begin{array}{c}\text { Positive } \\
\text { number } \\
(\%)\end{array}$ \\
\hline bla $_{\mathrm{VEB}}$ & $3,6,16,23^{*}, 26,28,30,33,37,38^{*}$, & $18(25.71)$ \\
& $46,48,50^{*}, 53^{*}, 56,60,61^{*}, 65^{*}$ & \\
bla $_{\mathrm{PER}}$ & $3,8,4,6,7^{*}, 13,20^{*}, 28,29,36^{*}$, & $18(25.71)$ \\
& $37,55^{*}, 56,61^{*}, 64^{*}, 65^{*}, 66^{*}, 67^{*}$ & $13(18.57)$ \\
bla $_{\mathrm{KPC}}$ & $3,4,6,16,28,36^{*}, 37,38^{*}, 43$, & \\
& $50^{*}, 56,66^{*}$ & $21(30)$ \\
bla $_{\mathrm{NDM}}$ & $6,7^{*}, 9,10,11,26,27^{*}, 28,29,30$, & $5(7.14)$ \\
& $36^{*}, 37,38^{*}, 43,46,53^{*}, 56,68$ & $1(1.42)$ \\
bla $_{\mathrm{IMP}}$ & $7^{*}, 23^{*}, 30,33,36^{*}$ & $1(1.42)$ \\
bla $_{\mathrm{VIM}}$ & 26 & $12(17.14)$ \\
bla $_{\mathrm{OXA}-23}$ & 60 & \\
bla $_{\mathrm{OXA}-48}$ & $6,7^{*}, 9,20^{*}, 26,28,37,38^{*}, 46,59,60,67^{*}$ & \\
bla $_{\mathrm{OXA}-51}$ & 59 & \\
*; indicates community-associated samples.
\end{tabular}

; indicates community-associated samples. 


\begin{tabular}{|c|c|c|c|c|c|c|}
\hline Sample No & 65 & 66 & 67 & 68 & 69 & 70 \\
\hline Sample & CSF & TAC & Blood & Blood & TAC & Urine \\
\hline Age & 42 & 82 & 84 & 88 & 87 & 47 \\
\hline Gender & Man & Man & Man & Women & Man & Man \\
\hline \multirow{2}{*}{ Holding dates } & 30.07 .2016 & 15.05 .2016 & 08.04 .2016 & 06.09 .2016 & 11.07.2016 & 22.06.2016 \\
\hline & 22.12 .2016 & 16.08 .2016 & 24.04 .2016 & 06.11 .2016 & 01.11 .2016 & 24.08 .2016 \\
\hline Holding time (day) & 145 & 93 & 16 & 61 & 113 & 62 \\
\hline Service & $\begin{array}{l}\text { ARICU - } \\
\text { IMICU } \\
\text { PCU }\end{array}$ & IMICU & IMICU & IMICU & IMICU & IDS \\
\hline $\begin{array}{l}\text { Comorbidity or additional } \\
\text { disease }\end{array}$ & IVTA - TSH & CRI & PTC & PTC & KOAH & NBS \\
\hline $\begin{array}{l}\text { Positive simultaneous breeding: } \\
\text { another example }\end{array}$ & Blood -TAC & Blood & TAC & Blood - Urine & TAC & Urine \\
\hline $\begin{array}{l}\text { Positive simultaneous growth: } \\
\text { other microorganism. }\end{array}$ & $\begin{array}{l}\text { Acinetobacter } \\
\text { spp. } \\
\text { Klebsiella } \\
\text { pneumoniae }\end{array}$ & $\begin{array}{l}\text { Acinetobacter } \\
\text { spp. }\end{array}$ & Candida spp. & $\begin{array}{l}\text { Acinetobacter spp. } \\
\text { Klebsiella spp. }\end{array}$ & $\begin{array}{l}\text { Acinetobacter } \\
\text { spp. }\end{array}$ & $\begin{array}{l}\text { Klebsiella } \\
\text { spp. }\end{array}$ \\
\hline $\begin{array}{l}\text { History of using antibiotics in } \\
\text { the last } 3 \text { months }\end{array}$ & NO & YES & YES & YES & YES & YES \\
\hline The fate of the patient & EX & EX & EX & $\mathrm{EX}$ & EX & Following \\
\hline
\end{tabular}




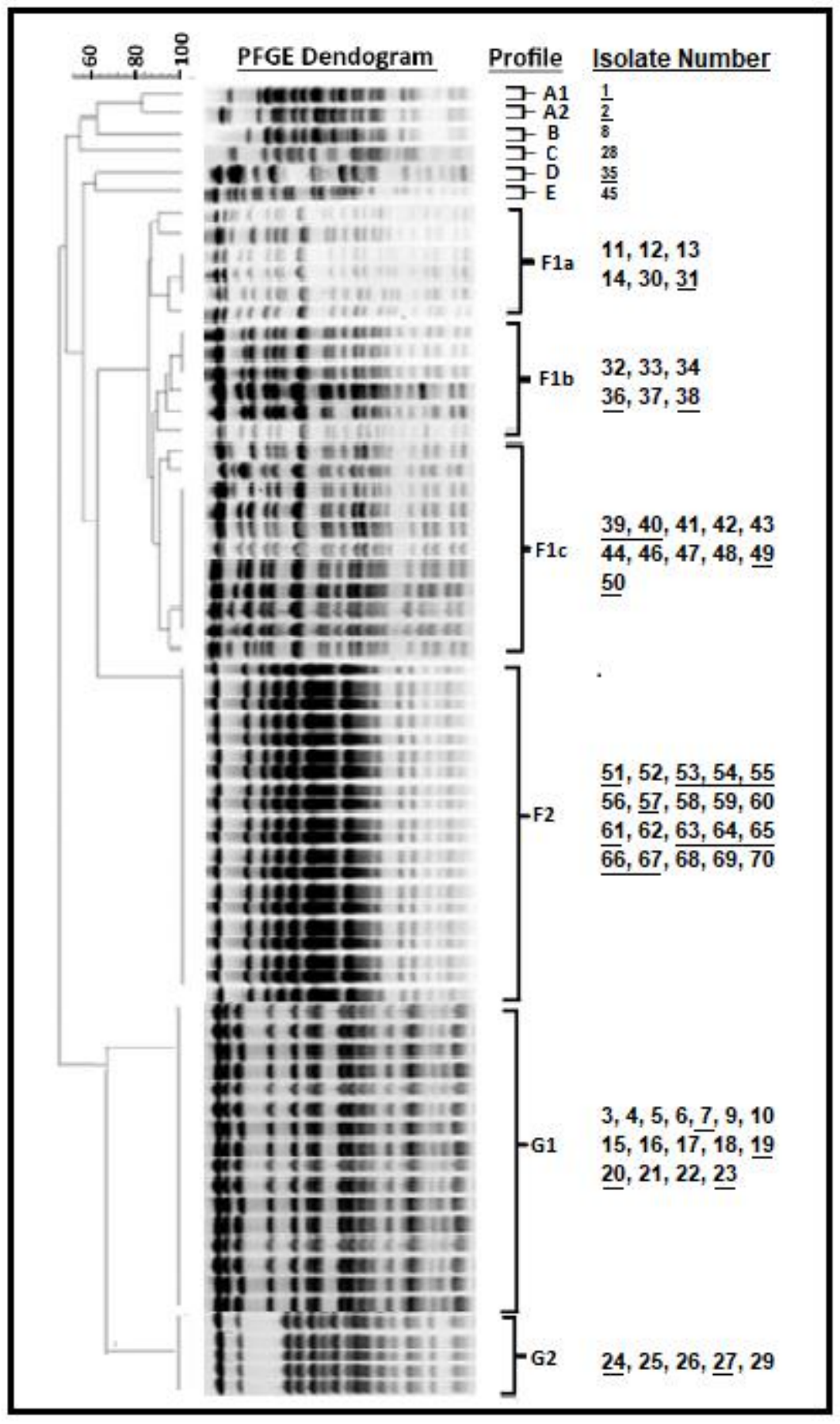

Fig. 1 PFGE analysis of P. aeruginosae strains generated seven major clusters (profile 1 (A1, A2, B, C, D, E), F1a, F1b, 
Figures

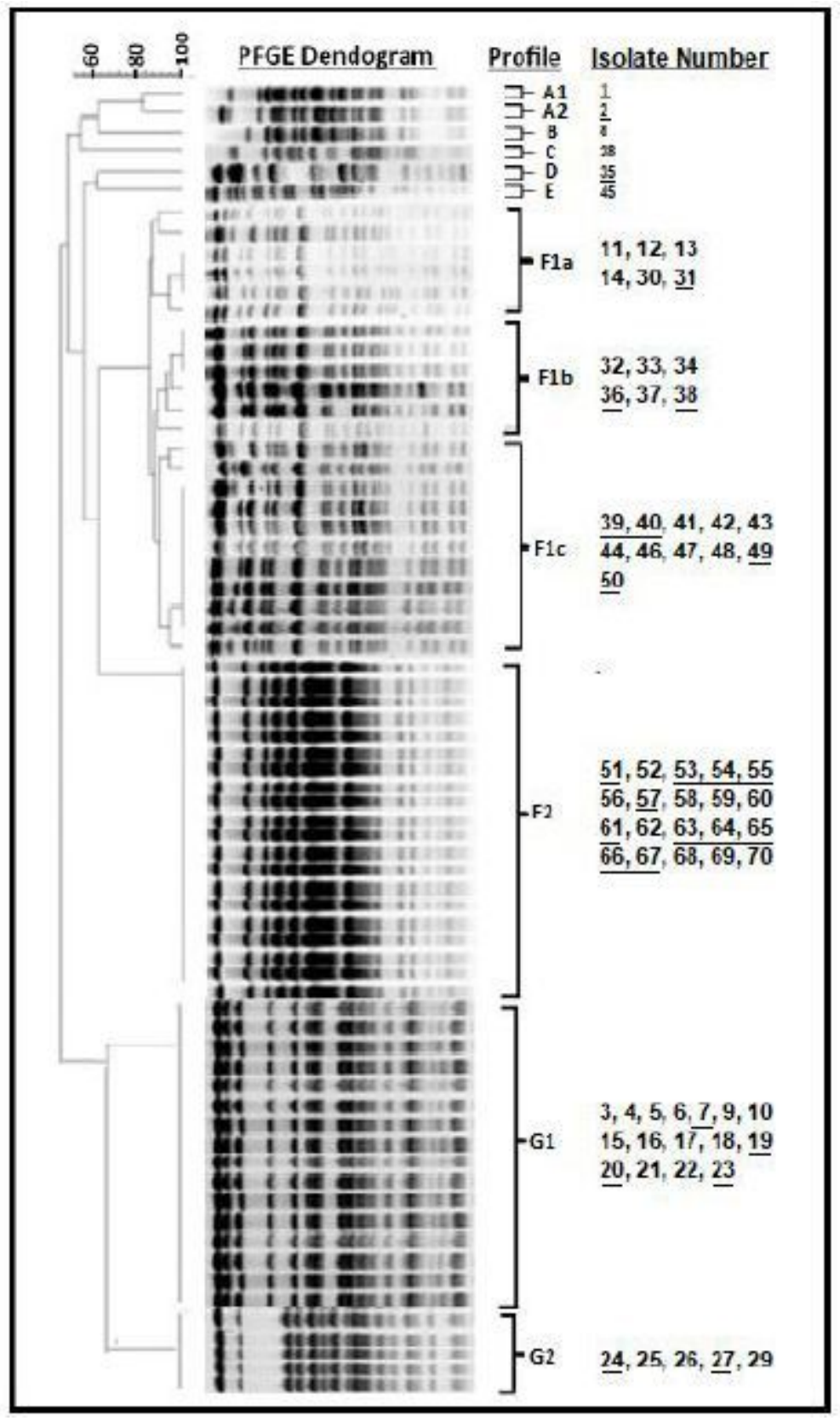

Figure 1

PFGE analysis of $P$. aeruginosae strains generated seven major clusters (profile 1 (A1, A2, B, C, D, E), F1a, F1b, F1c, F2, G1 and G2). Community-associated samples were shown as underlined. 